\title{
Effect of autologous platelet-rich plasma transfusion in the treatment of infertile women with thin endometrium and its implications in IVF cycles: a literature review
}

\author{
Ahmed Samy ${ }^{1}$ (D), Ahmed M. Abbas ${ }^{2 *}$, Ahmed Elmoursi ${ }^{3}$, Mohamed Elsayed ${ }^{4}$ and Reda S. Hussein ${ }^{2}$
}

\begin{abstract}
Background: Thin endometrium could be a major contributing factor in decreasing pregnancy rates with in-vitro fertilization. Several treatments have been studied in patients with thin endometrium, like hormonal therapy by $\mathrm{GnRH}$-agonist and estrogen. Additionally, vasoactive measures like aspirin, a mix of pentoxifylline, vitamin E, l-arginine, sildenafil, and intrauterine infusion of a growth factor such as G-CSF, and the recent application of regenerative medicine were reported in previous trials.

Main body of the abstract: We discuss here a new modality for thin endometrium treatment using platelet-rich plasma (PRP) administered as an intrauterine infusion. The purpose of this review is to evaluate the effectiveness of PRP in cases of infertility. All relevant articles addressing the use of PRP, published from January 2000 to September 2018, were reviewed and analyzed. The studies published on the PRP treatment model for thin endometrium in the gynecology field were mainly case series, pilot studies, or case reports.
\end{abstract}

Conclusion: In the current review, we found that the local administration of PRP is significantly effective in increasing pregnancy rates of infertile women with thin endometrium $<6 \mathrm{~mm}$.

Keywords: Endometrium, Infertility, Platelet-rich plasma, In vitro fertilization

\section{Background}

Infertility is a global public health issue; about $13 \%$ of the couples suffer from infertility. Implantation failure occurs, despite the effort of fertility clinics in the field of assisted reproductive technology (ART); therefore, highquality embryo and adequate receptive endometrial growth are required for successful implantation [1]. Pregnancy rates can be increased by increasing the endometrial thickness (ET); the minimum thickness required for implantation is $7 \mathrm{~mm}[2]$.

The human endometrium undergoes significant changes during embryo implantation; as its tissues contain receptors for growth factors, cytokines, and lipids that are vital for endometrial and embryonic

\footnotetext{
* Correspondence: bmr90@hotmail.com

${ }^{2}$ Department of Obstetrics and Gynecology, Faculty of Medicine, Assiut

University, Assiut, Egypt

Full list of author information is available at the end of the article
}

development; during which the ET affects the rate of successful implantation [3, 4]. Therefore, it has been important for clinicians to make sure that the ET and embryo quality is well measured or treated in case of being suboptimal. Since then, many strategies have been used to increase the ET and to improve its quality for embryo transfer: estrogen, low dose Aspirin, vaginal sildenafil, Pentoxifylline, and granulocyte-colony stimulating factor (G-CSF) intrauterine perfusion. However, these methods cannot improve all cases with a thin endometrium.

Platelet-rich Plasma (PRP) is a new model treatment for thin endometrium. It is a centrifuged fresh human blood containing a high concentration of platelets. PRP is prepared from the patient's own blood and contains many growth factors and cytokines such as vascular endothelial growth factor (VEGF), platelet-derived growth factor (PDGF), epidermal growth factor (EGF), transforming growth factor (TGF) and many other 
cytokines that can facilitate tissue regeneration and healing. It is found that PRP application improved endometrial regeneration in an animal model with ethanolinduced damaged endometrium [5]. Recently, PRP infusion was applied to humans, especially women who cannot respond to standard treatment.

The objective of this review is to summarize and evaluate the effectiveness of PRP as a treatment of thin endometrium in infertile women and its pivotal role in cases of in vitro fertilization (IVF).

\section{Main text}

A narrative review search was done using PubMed, MEDLINE, Scopus, Clinical Key, and Google scholar databases to investigate studies addressing PRP therapy in infertile women with refractory endometrium. We searched the databases from January 2000 to August 2018. We used "Platelet Rich Plasma", "PRP", "IVF", "thin endometrium", "infertility," and "Gynecology" as keywords for our search strategy.

The studies found for this review were mainly case reports, case series, letters, and small sample-sized pilot studies. We excluded studies that are performed on animals and studies that are concerned with other clinical uses of PRP. No randomized clinical trials were found on PRP use.

\section{The science of PRP PRP preparation}

Fresh whole blood collected from a peripheral vein is used for the preparation of PRP. Then, it is stored in acid citrate dextrose solution A (ACD-A) anticoagulant and processed to increase platelets through the separation of various components of blood [6]. Through activating platelets in PRP, cytokines, and growth factors (GFs) become bioactive and are secreted within $10 \mathrm{~min}$ after clotting. These factors include VEGF, TGF, PDGF, and EGF [7]. They can regulate cell migration, attachment, proliferation, and differentiation, and promote extracellular matrix accumulation. There are several methods for PRP preparation, with a difference in the speed and timing of centrifugation $[6,8]$.

\section{Types of PRP preparation}

There are different types of PRP preparations depending on the preparation method, the content of the sample, and the proposed application. The difference in preparations is attributed to the centrifugation time, speed, and anticoagulant use, while the content varies according to the predominant constituent (e.g., leukocytes, platelets, or growth factors) [9]. Four types of preparations can be obtained after centrifugation of whole blood. This classification is based on cell content and fibrin density, as proposed by Ehrenfest et al. [10]. Additionally, it was recommended by a multi-disciplinary consensus committee [11].

\section{Proposed mechanisms of action of PRP}

The mechanisms of PRP are not clear; however, laboratory studies have shown that the healing process is enhanced by the high concentration of growth factors in PRP [12]. PRP is superior to the recombinant human growth factor because platelet activation leads to the release of multiple growth factors and differentiation factors. Recently, the fibrin framework present over platelets was found to support the regenerative matrix, leading to the rapid organization of the proper morphological and molecular patterns for wound healing $[13,14]$.

Implantation failure is considered one of the major challenges facing clinicians in ART despite the significant advances that have been made in this field $[15,16]$. Adequate ET is a chief factor for implantation and pregnancy. Women who have persistent thin endometrium often do not go through embryo transfer [17]. Although no definite method was achieved, there are several methods have been described for endometrial preparation. The human endometrial tissue has receptors for growth factors, cytokines, adhesion molecules, and other factors that enhance endometrial and embryonic development [5].

\section{Approaches for thin endometrium management}

The thin endometrium may result from several causes or could be idiopathic. For example, the exposure to progesterone therapy for a long time in oral contraceptives may cause thinning of endometrium. Combined oral contraceptives started on menstrual days 1-3 cause a uniformly thin endometrium till in the late luteal phase [18]. In many IVF centers, combined oral contraceptives are used for different purposes and indications.

Here, we will discuss some of the approaches for thin endometrium treatment.

\section{Low dose aspirin}

Where "thin" endometrium could result from reduced endometrial blood flow, the use of the vasoactive drug may increase endometrial vascularity with resulting in improvement in endometrial growth. Weckstein et al. studied the effect of low dose aspirin with 28 oocyte donation recipients with a thin endometrium $(<7 \mathrm{~mm})$ [19]. The implantation and clinical pregnancy rates were significantly higher in women who received aspirin compared to those who did not use it, with no improvement in ET. This effect of the low dose aspirin could be due to the improved blood flow observed.

Another study by Hsieh et al. found that the rate of trilaminar endometrium (46.5\% vs. $26.2 \%)$ and pregnancy 
rates $(18.4 \%$ vs. $9.0 \%)$ after the administration of $(100 \mathrm{mg})$ aspirin from menstrual day 1 through pregnancy test in clomiphene citrate induced cycles [20].

\section{Pentoxifylline and vitamin $E$}

Pentoxifylline (as a vasodilator) and vitamin $\mathrm{E}$ as an antioxidant were used as suggested drugs by Ledee-Bataille et al. [21]. This combination was given to 18 oocyte recipients, who failed to develop a pre-ovulatory ET of at least $6 \mathrm{~mm}$ following vaginal E2 administration resulted in $72 \%$ significant improvement in ET and delivery rates.

\section{Sildenafil}

Vaginal sildenafil citrate has been tried in the treatment of patients with RIF. Sildenafil is a phosphodiesterase- 5 inhibitor with the vasodilatation effect of nitric oxide produced. The effect of vaginal sildenafil on the ET of infertile patients undergoing IVF treatment have demonstrated improved blood flow in uterine and endometrial growth, with higher implantation and ongoing pregnancy rates after administration vaginal sildenafil. Zinger et al. have reported two infertility patients with Asherman's syndrome's who achieved pregnancy after using vaginal sildenafil citrate $25 \mathrm{mg}$, four times a day for 614 days during the first half of their cycles [22].

\section{Estrogen}

While there have been many studies regarding estrogen therapy with different administration routes, the vaginal administration of estrogen results in the highest peak of serum estrogen and endometrial level. Therefore, it is considered the preferable way in cases in which the other routes are not effective [23].

Chen et al. have studied the effect of extended estradiol valerate administration during controlled ovarian hyperstimulation cycles and concluded that the average ET in the study group increased from 6.7 to $8.6 \mathrm{~mm}$ following the estradiol valerate therapy from 14 to 82 days [24]. The pregnancy rate in the study group was increased more than that of the control group (38.5 vs. $4.3 \%)$.

\section{GnRH-agonist}

The administration of GnRH-agonist improved pregnancy rate in patients who received a mid-luteal injection of a GnRH-agonist. Qublah et al. conducted a controlled randomized study with infertile patients with a thin endometrium $(<7 \mathrm{~mm})$ during an IVF cycle. Patients were randomized between taking a placebo and those who received triptorelin $0.1 \mathrm{mg}$ on ovum pick up day. Significantly higher implantation and pregnancy rates and ET were reported in the treated group compared to the placebo groups. These effects might be explained through the GnRH effect on endometrium [25].

\section{PRP for treatment of thin endometrium}

The adequate thickness of the endometrium is probably essential to accomplish a successful pregnancy in ART cycles [26-28]. While there is no agreement on the exact value that defines "thin endometrium", El-Toukhy et al. [17] suggested that thin endometrium defined as an ET that cannot reach the threshold for embryo implantation. Moreover, there is no ET value that precludes pregnancy, with previous viable pregnancy reported with ET of $3.7 \mathrm{~mm}$ [29]. Several reports have shown a correlation between a "thin endometrium" and low implantation rates $[30,31]$.

Weissman et al. [32] suggested a minimum ET of 7 $\mathrm{mm}$ to maximize pregnancy rates. Richter et al. [31] evaluated the relationship between ET and clinical outcome of IVF in 1294 infertility patients undergoing fresh embryo transfer. They found a higher ET in cycles resulting in pregnancy compared to cycles not resulting in pregnancy. Moreover, clinical pregnancy rates increased from $53 \%$ among patients with ET of $59 \mathrm{~mm}$ to $77 \%$ among patients with ET $\leq 16 \mathrm{~mm}$.

Chang et al. [33] conducted a prospective cohort trial to study the effect of PRP in women with thin endometrium undergoing FET. ET was significantly higher in the PRP group than in the control group $(7.65 \pm 0.22 \mathrm{~mm}$ vs. $6.52 \pm 0.31 \mathrm{~mm}, P<0.05$, respectively) with a lower cancelation rate for the PRP group $(P<0.01)$. This was reflected by having higher implantation and clinical pregnancy rate in favor of the PRP group $(27.94 \%$ vs. $11.67 \%, P<0.05$, respectively). The analysis of the PRP solution showed higher levels of platelet-derived growth factor (PDGF)-AB, PDGF-BB, and transforming growth factor (TGF) $\beta$ in comparison to peripheral blood.

These results were on par with the data of Kim et al. [34] that proposed higher implantation, pregnancy, and live birth rates with refractory thin endometrium with PRP administration. Likewise, two additional studies, including one randomized trial, evaluated the impact of PRP in the endometrial growth in cases with poor endometrium [5, 35]. Their data proposed that the use of PRP could significantly improve thin lining. However, this data needs to be confirmed by large randomized and controlled studies. Studies investigated autologous PRP in the state of thin endometrium are summarized in Table 1.

\section{PRP for refractory endometrium}

The endometrium has an important role in achieving optimal outcomes of ART. Endometrial growth after inadequate ovarian stimulation may be insufficient, leading to poor results of IVF cycles. Different strategies have been recommended to improve ET, especially in resistant cases. PRP is a new therapy that has been tried before in those patients (Table 2). Five infertile women, in 
Table 1 Autologous platelet-rich plasma (PRP) infusion in cases of thin endometrium

\begin{tabular}{|c|c|c|c|c|c|}
\hline Author, year & Study design & Population & Sample size & Reproductive outcomes & Secondary outcomes \\
\hline $\begin{array}{l}\text { Kim } \\
\text { et al. (2019) [34] }\end{array}$ & $\begin{array}{l}\text { Prospective } \\
\text { interventional } \\
\text { study }\end{array}$ & $\begin{array}{l}\text { Patients with history of } \\
\geq 2 \text { failed IVF cycles and } \\
\text { refractory thin } \\
\text { endometrium ( }<7 \mathrm{~mm}) \text {. }\end{array}$ & $\begin{array}{l}24 \text { patients } \\
\text { were } \\
\text { compared } \\
\text { against their } \\
\text { previous } \\
\text { cycles }\end{array}$ & $\begin{array}{l}\text { PRP improved implantation, } \\
\text { pregnancy and live birth rates in } \\
\text { comparison to their previous cycles. }\end{array}$ & \\
\hline $\begin{array}{l}\text { Chang } \\
\text { et al. (2019) [33] }\end{array}$ & $\begin{array}{l}\text { Prospective } \\
\text { interventional } \\
\text { study }\end{array}$ & $\begin{array}{l}\text { Patients with thin } \\
\text { endometrium }<7 \mathrm{~mm} \\
\text { and prior canceled FET. }\end{array}$ & $\begin{array}{l}34 \text { in PRP } \\
\text { group and } 30 \\
\text { in control. }\end{array}$ & $\begin{array}{l}\text { PRP had higher ET and lower } \\
\text { cancellation rate. } \\
\text { Higher implantation and clinical } \\
\text { pregnancy rate in favor of PRP } \\
\text { ( } 27.94 \% \text { vs } 11.67 \%, P<.05 ; 44.12 \% \\
\text { vs } 20 \%, P<.05 \text {, respectively). }\end{array}$ & $\begin{array}{l}\text { Higher levels of PDGF-AB, PDGF- } \\
\text { BB, and TGF- } 3 \text { in favor of PRP } \\
\text { group in comparison to periph } \\
\text { eral blood. }\end{array}$ \\
\hline $\begin{array}{l}\text { Eftekhar } \\
\text { et al. (2018) [35] }\end{array}$ & $\begin{array}{l}\text { Randomized } \\
\text { clinical trial }\end{array}$ & $\begin{array}{l}\text { Women with poor } \\
\text { endometrial response to } \\
\text { standard hormonal } \\
\text { preparation (ET }<7 \mathrm{~mm} \\
\text { in the 13th day of FET } \\
\text { cycle }\end{array}$ & $\begin{array}{l}40 \text { in PRP and } \\
43 \text { in control }\end{array}$ & $\begin{array}{l}\text { PRP higher ET }(0.001) \text {, implantation } \\
(P=0.002) \text { and pregnancy } \\
\text { rate }(P=0.044) .\end{array}$ & \\
\hline $\begin{array}{l}\text { Wang } \\
\text { et al. (2018) }\end{array}$ & $\begin{array}{l}\text { Prospective } \\
\text { interventional } \\
\text { study }\end{array}$ & $\begin{array}{l}\text { Patients with recurrent } \\
\text { implantation failure due } \\
\text { to suboptimal } \\
\text { endometrial pattern, } \\
\text { women with } \geq 2 \\
\text { canceled cycles due to } \\
\text { thin endometrial lining }\end{array}$ & $\begin{array}{l}20 \text { patients } \\
\text { were } \\
\text { compared to } \\
\text { their previous } \\
\text { data }\end{array}$ & $\begin{array}{l}\text { Successful endometrial expansion after } \\
\text { PRP }(5.55 \pm 0.71 \mathrm{~mm} \text { vs } 7.82 \pm 1.04 \\
\mathrm{mm}, P<0.001 \text {, for pre- and post-PRP } \\
\text { respectively). Pregnancy was positive in } \\
12 \text { cases after PRP infusion }(60 \%) . .\end{array}$ & $\begin{array}{l}\text { In vitro analysis demonstrated } \\
\text { that PRP significantly increased } \\
\text { growth, migration, and adhesion } \\
\text { of endometrial mesenchymal } \\
\text { stem cells. }\end{array}$ \\
\hline
\end{tabular}

Abbreviations: PRP platelet-rich plasma, FET frozen embryo transfer, ET endometrial thickness, PDGF platelet-derived growth factor, TGF- $\beta$ transforming growth factor-beta

whom frozen embryo transfer was canceled due to inadequate endometrium, underwent PRP intrauterine infusion after 10 days of estradiol valerate per os. When the endometrium was still detected to be $<7 \mathrm{~mm}$ after $72 \mathrm{~h}$, a second intrauterine PRP infusion was performed. Interestingly, endometrial thickness $>7 \mathrm{~mm}$ was achieved in all five patients, and they all had a positive pregnancy following the embryo transfer. Four cases experienced ongoing pregnancy, with one case had an early miscarriage from chromosomal abnormalities (45 $\mathrm{XO}$ after the analysis of postconceptional products) [5].

Colombo et al. [38] evaluated eight patients who underwent PRP treatment. They included women with more than three cancelled cryo-transfers owing to poor endometrial growth $(<6 \mathrm{~mm})$ with a negative hysteroscopic screening for endometrial pathology. After the

Table 2 Autologous platelet-rich plasma (PRP) infusion in cases of refractory endometrium

\begin{tabular}{|c|c|c|c|c|}
\hline Author, year & $\begin{array}{l}\text { Study } \\
\text { design }\end{array}$ & Population & $\begin{array}{l}\text { Sample } \\
\text { size }\end{array}$ & Study outcomes \\
\hline $\begin{array}{l}\text { Chang et al. } \\
\text { (2015) [1] }\end{array}$ & $\begin{array}{l}\text { Prospective } \\
\text { cohort } \\
\text { study }\end{array}$ & $\begin{array}{l}\text { Women who have a poor endometrial response }(<7 \\
\mathrm{mm}) \text { to the standard hormonal preparation of FET } \\
\text { and had to cancel their embryo transfer. }\end{array}$ & 5 & $\begin{array}{l}\text { Successful endometrial expansion and transfer for } \\
\text { all patients with pregnancy detected in } 4 \text { cases }\end{array}$ \\
\hline $\begin{array}{l}\text { Zadehmodarres } \\
\text { et al. (2017) [2] }\end{array}$ & $\begin{array}{l}\text { Prospective } \\
\text { cohort } \\
\text { study }\end{array}$ & $\begin{array}{l}\text { Patients with a history of canceled FET due to } \\
\text { inadequate endometrium. }\end{array}$ & 10 & $\begin{array}{l}\text { ET increased in all patients with Five of them were } \\
\text { pregnant }\end{array}$ \\
\hline $\begin{array}{l}\text { Molina et al. } \\
\text { (2018) [36] }\end{array}$ & $\begin{array}{l}\text { Prospective } \\
\text { cohort } \\
\text { study }\end{array}$ & Patients with a history of refractory endometrium. & 19 & $\begin{array}{l}\text { ET } \geq 7 \mathrm{~m} \text { was detected after the first PRP use and } \\
\text { all cases experienced } E T \geq 9 \mathrm{~mm} \text { after the second } \\
\text { use. Embryo transfer was conducted in the entire } \\
\text { study group. Positive pregnancy in } 73.7 \% \text { with live } \\
\text { birth in } 26.3 \%\end{array}$ \\
\hline $\begin{array}{l}\text { Tandulwadkar } \\
\text { et al. (2017) }\end{array}$ & $\begin{array}{l}\text { Prospective } \\
\text { cohort } \\
\text { study }\end{array}$ & $\begin{array}{l}\text { Women experienced suboptimal growth or } \\
\text { vascularity despite standard dose of hormonal } \\
\text { preparation. Women with }>2 \text { canceled cycles or } \\
\text { recurrent implantation failure due to poor } \\
\text { endometrial lining. }\end{array}$ & 68 & $\begin{array}{l}\text { ET and vascularity increased post- PRP. Clinical } \\
\text { pregnancy was detected in } 45.1 \% \text {. }\end{array}$ \\
\hline $\begin{array}{l}\text { Jang et al. } \\
\text { (2017) [37] }\end{array}$ & $\begin{array}{l}\text { Animal } \\
\text { study }\end{array}$ & Murine animal model. & 60 & $\begin{array}{l}\text { PRP stimulated and accelerated regeneration of the } \\
\text { endometrium with decreased fibrosis. }\end{array}$ \\
\hline
\end{tabular}


application of PRP, in seven patients out of eight, the ET was improved more than $6.5 \mathrm{~mm}$ with an average of 6.9 $\mathrm{mm}$. A positive test for beta-human chorionic gonadotropin was found in six women. They concluded that PRP administration could improve the multiple implantation failures caused by the inefficient expression of adhesion molecules.

In the same way, Zadehmodarres et al. evaluated 10 patients with a history of canceled cycles due to inadequate endometrial growth $(<7 \mathrm{~mm})$ [2]. At $48 \mathrm{~h}$ after the first PRP application, the ET increased and reached more than $7 \mathrm{~mm}$ after the second PRP application in all patients. Five patients became pregnant (50\%) after embryo transfer with a normal pregnancy in four of them. They concluded that PRP was effective for endometrial growth in infertile women with a thin endometrium.

Molina et al. [36] made a prospective design on 19 infertile patients undergoing High Complexity ART, with a previous history of refractory endometrium and at least one failed IVF attempt and with the exclusion of patients with no history of failed IVF or without refractory endometrium; and the patients aged between 33 and 45 years. An infusion of autologous one cc PRP serum was applied into the uterine cavity, on the tenth day of HRT with estradiol valerate, and again at $72 \mathrm{~h}$ of the first administration, using TVS to determine the ET.

After applying the second PRP infusion, all populations in the study achieved ET greater than $9 \mathrm{~mm}$ with 14 cases $(73.7 \%)$ of positive pregnancy and 5 cases of false pregnancy test [36].

Jang et al. [37], in an animal model, tested the role of PRP in endometrial regeneration after ethanol-induced damage. They found that intrauterine infusion of autologous PRP stimulated and accelerated the endometrial regeneration and decreased fibrosis.

\section{PRP for repeated implantation failure}

Repeated implantation failure (RIF) is defined as a failure to conceive following several embryo transfers in IVF cycles. Numerous factors are involved in the implantation process as embryo quality, endometrial receptivity, and immunological factors [39]. Several methods have been evaluated before for RIF management, but no agreement on which is most effective. These methods include blastocyst transfer, assisted hatching, endometrial scratching, and immune therapy. Recently, the intrauterine infusion of PRP has been used to promote endometrial growth and receptivity $[1,40]$.

Nazari et al. [39] included 20 women with a history of RIF to evaluate the effectiveness of PRP in increasing the pregnancy rate in RIF patients. After applying exclusion criteria which were uterine, chromosomal and genetic abnormalities, and hematological, immunological, and hormonal disorders; and inclusion criteria with age below 40 years and body mass index (BMI) below $30 \mathrm{~kg} /$ $\mathrm{m}^{2}$, they reported that 18 of the 20 participants $(90 \%)$ became pregnant. Sixteen clinical pregnancies were recorded, and their pregnancies were ongoing at the time of the study, 1 molar pregnancy and 1 miscarriage. Their conclusions were PRP was an effective method in improving pregnancy outcomes in RIF patients [39].

\section{Conclusions}

In conclusion, according to the previous studies, we found that the local administration of PRP is significantly effective in increasing pregnancy rates of infertile women with refractory endometrium with $\mathrm{ET}<6 \mathrm{~mm}$, therefore increasing endometrial receptivity and vascularity as it contains the growth factors and other cytokines that have positive effects on local tissue repair and endometrial receptivity. There is currently evidence to support the effectiveness of local administration of PRP in successful implantation. Since the PRP is autologous, it is easily obtained, inexpensive, and a safe preparation protocol as it is derived from the patient's own blood. However, further studies should be conducted with a large number of participants to investigate more protocols in refractory endometrium management.

\section{Abbreviations}

ART: Assisted reproductive technology; EGF: Epidermal growth factor; ET: Endometrial thickness; G-CSF: Granulocyte-colony stimulating factor; IVF: In vitro fertilization; PDGF: Platelet-derived growth factor; PRP: Plateletrich Plasma; RIF: Repeated implantation failure; TGF: Transforming growth factor; VEGF: Vascular endothelial growth factor

\section{Acknowledgements}

Not applicable.

\section{Authors' contributions}

AS and AMA contributed substantially to the conception and design of the study. AE and ME performed the database search. AS and AMA supervised the research and findings of the work. AE and ME wrote the manuscript. AS and $A E$ checked the references. AMA and RSH reviewed and critically revised the article before submission for spelling and grammar. RSH revised the literature search and drafted the studies in table form. All authors discussed the results and contributed to the final manuscript and provided final approval of the version to publish.

\section{Funding \\ None.}

\section{Availability of data and materials}

Not applicable.

Ethics approval and consent to participate Not applicable.

\section{Consent for publication}

Not applicable.

\section{Competing interests}

The authors declare that they have no competing interests.

\section{Author details}

${ }^{1}$ Department of Obstetrics and Gynecology, Faculty of Medicine, Cairo University, Cairo, Egypt. ${ }^{2}$ Department of Obstetrics and Gynecology, Faculty of Medicine, Assiut University, Assiut, Egypt. ${ }^{3}$ Faculty of Medicine, Al-Azhar 
University, Cairo, Egypt. ${ }^{4}$ Faculty of Pharmacy, Mansoura University, Mansoura, Egypt.

\section{Received: 7 August 2019 Accepted: 27 January 2020}

Published online: 04 February 2020

\section{References}

1. Chang Y, Li J, Chen Y et al (2015) Autologous platelet-rich plasma promotes endometrial growth and improves pregnancy outcome during in vitro fertilization. Int J Clin Exp Med 8:1286-1290

2. Zadehmodarres S, Salehpour S, Saharkhiz N, Nazari L (2017) Treatment of thin endometrium with autologous platelet-rich plasma: a pilot study. JBRA assisted reproduction. 21(1):54

3. Simon C, Moreno C, Remohi J, Pellicer A (1998) Molecular interactions between embryo and uterus in the adhesion phase of human implantation. Hum Reprod 13:219-232

4. Paria BC, Song H, Dey SK (2001) Implantation: molecular basis of embryouterine dialogue. Int J Dev Biol 45:597-605

5. Dawood AS, Salem HA (2018) Current clinical applications of platelet-rich plasma in various gynecological disorders: An appraisal of theory and practice. Clin Exp Reprod Med 45:67-74

6. Amable PR, Carias RB, Teixeira MV et al (2013) Platelet-rich plasma preparation for regenerative medicine: optimization and quantification of cytokines and growth factors. Stem Cell Res Ther 4:67

7. Lee JW, Kwon OH, Kim TK et al (2013) Platelet-rich plasma: quantitative assessment of growth factor levels and comparative analysis of activated and inactivated groups. Arch Plast Surg 40:530-535

8. Dhurat R, Sukesh M (2014) Principles and methods of preparation of platelet-rich plasma: a review and author's perspective. J Cutan Aesthet Surg 7:189-197

9. Anitua E, Sanchez M, Orive G (2011) The importance of understanding what is platelet-rich growth factor (PRGF) and what is not. J Shoulder Elbow Surg 20:e23-e24

10. Ehrenfest DM, Andia I, Zumstein MA, Zhang CQ, Pinto NR, Bielecki T (2014) Classification of platelet concentrates (Platelet-Rich Plasma-PRP, Platelet-Rich Fibrin-PRF) for topical and infiltrative use in orthopedic and sports medicine: current consensus, clinical implications and perspectives. Muscles Ligaments Tendons J 4(1):3

11. Ehrenfest DM, Bielecki T, Mishra A et al (2012) In search of a consensus terminology in the field of platelet concentrates for surgical use: plateletrich plasma (PRP), platelet-rich fibrin (PRF), fibrin gel polymerization and leukocytes. Curr Pharm Biotechnol 13(7):1131-1137

12. International Cellular Medicine Society. Platelet Rich plasma (PRP) guidelines [Internet]. Las Vegas: International Cellular Medicine Society; 2011 [cited 2018 Aug 18]. Available from: http://www.cellmedicinesociety.org/icmsguidelines/guidelines.

13. Sundman EA, Cole BJ, Karas $V$ et al (2014) The anti inflammatory and matrix restorative mechanisms of platelet-rich plasma in osteoarthritis. Am J Sports Med 42:35-41

14. Raja VS, Naidu EM (2008) Platelet-rich fibrin: evolution of a secondgeneration platelet concentrate. Indian J Dent Res 19(1):42

15. Das M, Holzer HE (2012) Recurrent implantation failure: gamete and embryo factors. Fertil Steril 97:1021-1027

16. D Ly K, Aziz N, Safi J, Agarwal A. Evidence-based management of infertile couples with repeated implantation failure following IVF. Curr Women's Health Rev 2010;6:200-218.

17. El-Toukhy T, Coomarasamy A, Khairy M et al (2008) The relationship between endometrial thickness and outcome of medicated frozen embryo replacement cycles. Fertil Steril 89:832-839

18. Grow DR, Iromloo K (2006) Oral contraceptives maintain a very thin endometrium before operative hysteroscopy. Fertil Steril 85:204-207

19. Weckstein LN, Jacobson A, Galen D et al (1997) Low-dose aspirin for oocyte donation recipients with a thin endometrium: prospective, randomized study. Fertil Steril 68:927-930

20. Hsieh YY, Tsai HD, Chang CC et al (2000) Low-dose aspirin for infertile women with thin endometrium receiving intrauterine insemination: a prospective, randomized study. J Assist Reprod Genet 17:174-177

21. Ledee-Bataille N, Olivennes F, Lefaix JL et al (2002) Combined treatment by pentoxifylline and tocopherol for recipient women with a thin endometrium enrolled in an oocyte donation programme. Hum Reprod 17 : $1249-1253$
22. Zinger M, Liu JH, Thomas MA (2006) Successful use of vaginal sildenafil citrate in two infertility patients with Asherman's syndrome. J Womens Health (Larchmt). 15:442-444

23. Tourgeman DE, Slater CC, Stanczyk FZ, Paulson RJ (2001) Endocrine and clinical effects of micronized estradiol administered vaginally or orally. Fertil Steril 75:200-202

24. Chen MJ, Yang JH, Peng FH et al (2006) Extended estrogen administration for women with thin endometrium in frozen-thawed in-vitro fertilization programs. J Assist Reprod Genet. 23:337-342

25. Qublah H, Amarin Z, Al-Quda M et al (2008) Luteal phase support with GnRH-a improves implantation and pregnancy rates in IVF cycles with endometrium of $<7 \mathrm{~mm}$ on day of egg retrieval. Hum Fertil (Camb). 11:43-47

26. Zhang X, Chen CH, Confino E (2005) Increased endometrial thickness is associated with improved treatment outcome for selected patient undergoing in vitro fertilization: embryo transfer. Fertil Steril 83:336-340

27. Zenke U, Chetkowski RJ (2004) Transfer and uterine factors are the major recipient related determinants of success with donor eggs. Fertil Steril 82: 850-856

28. McWilliams GD, Frattarelli JL (2007) Changes in measured endometrial thickness predict in vitro fertilization success. Fertil Steril 88:74-81

29. Check JH, Cohen R (2011) Live fetus following embryo transfer in a women with diminish egg reserve whose maximal endometrial thickness was less than $4 \mathrm{~mm}$. Clin Exp Obstet Gynecol. 38:330-332

30. Abdalla HI, Brooks AA, Johnson MR et al (1994) Endometrial thickness: a predictor of implantation in ovum recipients. Hum Reprod 9:363-365

31. Richter KS, Bugge KR, Bromer JG, Levy MJ (2007) Relationship between endometrial thickness and embryo implantation, based on 1294 cycles of in vitro fertilization with transfer of two blastocyst-stage embryos. Fertil Steril 87:53-59

32. Weissman A, Gotlieb L, Casper RF (1999) The detrimental effect of increased endometrial thickness on implantation and pregnancy rates and outcome in in vitro fertilization program. Fertil Steril 71:147-149

33. Chang Y, Li J, Wei L-n, Pang J, Chen J, Liang X. Autologous platelet-rich plasma infusion improves clinical pregnancy rate in frozen embryo transfer cycles for women with thin endometrium. Medicine 2019;98.

34. Kim H, Shin JE, Koo HS, Kwon H, Choi DH, Kim JH (2019) Effect of autologous platelet-rich plasma treatment on refractory thin endometrium during the frozen embryo transfer cycle: A pilot study. Frontiers Endocrinol. 10

35. Eftekhar M, Neghab N, Naghshineh E, Khani P (2018) Can autologous platelet rich plasma expand endometrial thickness and improve pregnancy rate during frozen-thawed embryo transfer cycle? A randomized clinical trial. Taiwanese J Obstet Gynecol. 57:810-813

36. Molina A, Sánchez J, Sánchez W, Vielma V (2018) Platelet-rich plasma as an adjuvant in the endometrial preparation of patients with refractory endometrium. JBRA Assisted Reproduction. 22(1):42-48

37. Jang HY, Myoung SM, Choe JM et al (2017) Effects of autologous plateletrich plasma on regeneration of damaged endometrium in female rats. Yonsei Med J. 58:1195-1203

38. Colombo GV, Fanton V, Sosa D, et al. Use of platelet rich plasma in human infertility. J Biol Regul Homeost Agents 2017;31(2 Suppl. 2):179-182.

39. Nazari L, Salehpour S, Hoseini S, Zadehmodarres S, Ajori L (2016) Effects of autologous platelet-rich plasma on implantation and pregnancy in repeated implantation failure: a pilot study. Int J Reprod Biomed (Yazd) 14:625-628

40. Salehpour S, Zamaniyan M, Saharkhiz N et al (2016) Does intrauterine saline infusion by intrauterine insemination (IUI) catheter as endometrial injury during IVF cycles improve pregnancy outcomes among patients with recurrent implantation failure? An RCT. Int J Reprod Biomed (Yazd) 14:583-588

\section{Publisher's Note}

Springer Nature remains neutral with regard to jurisdictional claims in published maps and institutional affiliations. 